\title{
Estudio de la progresividad del Impuesto Sobre la Renta de personas Físicas en México
}

\author{
Study of the progressivity of the Personal Income Tax in Mexico \\ Eduardo Ramírez Cedillo*
}

Universidad Autónoma Metropolitana, México

Recibido el 15 de noviembre de 2019; aceptado el 02 de marzo de 2020

Disponible en Internet el: 05 de marzo de 2020

\section{Resumen}

La inequidad en la distribución del ingreso es una constante que se repite en todo el mundo en mayor o menor medida, los países desarrollados generalmente son menos inequitativos que los países en vías de desarrollo. Uno de los instrumentos que son utilizados con frecuencia para intentar reducir la inequidad y mejorar la distribución son los impuestos directos, particularmente los destinados a las personas, ya que pueden diseñarse de tal manera que resulten progresivos. La disyuntiva en el tema de la progresividad impositiva tiene que ver con la magnitud y qué tanto se mantiene, dados los incrementos del ingreso de las personas. A raíz de que el SAT (Servicio de Administración Tributaria) apertura la información de las declaraciones fiscales de forma anónima, es posible analizar la progresividad en México para diferentes tipos de contribuyente. En este documento se optó por el ISRPF (Impuestos Sobre la Renta de Personas físicas) para los años de 2010 a 2015, los resultados ofrecen evidencia de progresividad y cambios en la concentración y distribución del ingreso aun cuando resultan insuficientes para modificar la distribución del ingreso en el mediano plazo.

\footnotetext{
*Autor para correspondencia

Correo electrónico ramceed@gmail.com (E. Ramírez Cedillo).

La revisión por pares es responsabilidad de la Universidad Nacional Autónoma de México.

http://dx.doi.org/10.22201/fca.24488410e.2021.2654

0186- 1042/@ 2019 Universidad Nacional Autónoma de México, Facultad de Contaduría y Administración. Este es un artículo

Open Access bajo la licencia CC BY-NC-SA (https://creativecommons.org/licenses/by-nc-sa/4.0/)
} 
Código JEL: D31, E62, H24

Palabras claves: Impuesto Sobre la Renta; Progresividad; Distribución del ingreso

\begin{abstract}
The inequality in income distribution is a constant that is repeated throughout the world to a greater or lesser extent, industrialized countries are generally less inequitable than developing countries, one of the instruments that are frequently used to try to reduce inequality and better distribution are direct taxes and particularly those for people as they can be designed in such a way that they are progressive, but the dilemma with progressivity has to do with the magnitude and how much is maintained given the income increases of people. As a result of the SAT (Tax Administration Service) opening the information of the tax returns anonymously, it is possible to analyze the progressivity in Mexico for different types of taxpayers in this document, the ISRPF (Income Taxes of Individuals) for the years from 2010 to 2015, the results offer evidence of progressivity and changes in the concentration and distribution of income even when they are insufficient to modify the distribution of income in the medium term.
\end{abstract}

JEL Code: D31, E62, $\mathrm{H} 24$

Keywords: Income tax; Progressivity; Income distribution

\title{
Introducción
}

En los últimos años el tema de la distribución del ingreso ha tomado una amplia importancia, como lo denotan los trabajos realizados por Stiglitz (2012), Atkinson (2015), Deaton (2015), Mullainathan y Shafir (2016) y por supuesto Piketty (2014), así mismo diversos organismos internacionales como la CEPAL (CEPAL 2018; Castillo, 2015), Banco Mundial (Massina y Silva, 2017; Lange et al., 2018) y organizaciones como OXFAM (Fuentes-Nieva, 2014; Esquivel, 2015; Hardoon et al., 2016; Hardoon, 2017) también han contribuido en la discusión. En todos los casos existe una amplia coincidencia sobre el avance en la concentración del ingreso y de las afectaciones o inconveniencias que ello genera, además de establecer elementos que se consideran claves en la explicación del fenómeno y que tienen que ver con factores políticos, institucionales, sociales y por supuesto económicos. Así mismo, se establecen alternativas de solución coadyuvantes a la reversión de la concentración del ingreso.

La concentración del ingreso en México al igual que en muchos países y regiones del mundo es una realidad inherente a la propia dinámica de la economía de mercado, por lo que es crucial que se cuente con instrumentos de política económica que puedan atenuar y revertir dicha condición. En materia de política fiscal se cuenta con un instrumento que resulta crucial en la distribución del ingreso denominado impuesto progresivo, su finalidad principal 
consiste en generar un esquema de distribución del ingreso que resulte menos inequitativo que el logrado por el mercado.

La idea de los impuestos progresivos no es nueva y de acuerdo con Goldschmidt (1941a), dichos impuestos son una contribución que se hace necesaria en tiempos de crisis explosivas como son las que devienen de las guerras y sus consecuencias, por tanto, pueden ser vistos como un impuesto de emergencia. De tal manera, como lo señala el autor, si ha habido guerras desde los orígenes de la humanidad es posible pensar en impuesto de emergencia desde entonces.

Latinoamérica en los años posteriores a su Independencia tornó a la instauración de impuestos directos con la intención de participar en la distribución de la renta y promover el desarrollo económico. No obstante, estos primeros pasos tuvieron poco éxito debido a la falta de experiencia, la presencia de actos de corrupción y la carencia de un catastro organizado (Pinto, 2012). En la actualidad la mayoría de los países contemplan en sus sistemas tributarios impuestos directos con cierto nivel de progresividad (Estrada y González, 2014), el problema es que los impuestos progresivos son un componente secundario de su recaudación por lo que en términos generales la recaudación resulta regresiva (Mahon, et al., 2015).

En México los indicadores sociales al respecto de la distribución del ingreso y la pobreza en los últimos años han presentado un comportamiento que puede calificarse de no satisfactorio aun cuando se han tenido ciertos avances; en 2010 el coeficiente de GINI fue de 45.3 mientras que para el año 2016 registraba 43.4, siendo el nivel más bajo en todo el periodo, respecto a la pobreza en 2010 se registraba que el $46.10 \%$ de la población se encontraba bajo la línea de la pobreza a nivel nacional mientras que en 2016 se había reducido a 43.6\%. Aprovechando la apertura de la información de las declaraciones fiscales por parte del SAT (Servicio de Administración Tributaria) el presente documento tiene por objetivo aportar evidencia al respecto de la progresividad que tiene el impuesto sobre la renta de personas físicas (ISRPF), valorando con ello si coadyuva en mejorar la distribución del ingreso. Para tal fin el documento se integra por un apartado (II) que revisa la teoría respecto a los impuestos progresivos, para después continuar con (III) la exploración de los impuestos en el país y las cifras relativas a la distribución del ingreso. Posteriormente con los datos sobre las declaraciones de impuestos disponibles en el portal del SAT se procede a realizar un estudio de los años de 2010 a 2015 (IV) sobre la progresividad del impuesto, por último, se ofrece una conclusión al respecto.

\section{Revisión de la literatura}

Existe una polémica persistente al respecto de los impuestos progresivos, para la gran mayoría resulta claro que su uso obedece a la necesidad de distribución del ingreso dentro de la 
sociedad, ya que aun cuando los mercados sean competitivos y la sociedad sea relativamente homogénea siempre existirá algún margen de desigualdad (Friedman, 1948), denotado en algunos casos por grupos vulnerables como son: niños, enfermos y ancianos (Goldschmidt, 1941a). Por tal motivo el impuesto progresivo implica una condición en la cual es posible pensar que algunas personas podrían generar impuestos negativos mientras otros enfrentarían tasas tributarias medias mayores (Musgrave 1966).

La polémica es abordada por Goldschmidt (1941a, 1941b), quien realiza una disertación al respecto del impuesto progresivo vinculada a la lucha de clases, en la cual los propietarios de los medios de producción están dispuestos a recurrir a cualquier tipo de acción que esté a su alcance con tal de no pagar un impuesto que se considera injusto, un robo, una contribución sobre el ahorro o una multa al éxito. De acuerdo con Goldschmidt (1941a) si el funcionamiento del sistema capitalista sustenta su dinámica en la acumulación de capital, salvo en condiciones excepcionales, debería de aceptar la implementación de un impuesto progresivo con el cuidado necesario para que éste no estorbara en el proceso de acumulación. Sin embargo, a decir del autor "hasta la fecha no nos ha sido concedido el espectáculo de ver morir de inanición, a causa del impuesto progresivo a ningún especulador". En la actualidad, una de las principales objeciones sobre los impuestos progresivos radica en el impacto negativo que generan sobre el crecimiento y la merma en la obtención de los ingresos públicos, como ha sido estudiado por Koester y Kormendi (1989) quienes aportan evidencia sobre la disminución de la progresividad fiscal y su efecto sobre el mejoramiento del crecimiento económico. Mientras que Engen y Skinner (1999) encuentran relación negativa entre los tipos impositivos medios y el crecimiento económico, al igual que Padovano y Galli (2007), Widmalm (2001) y Arnold (2008) para el caso de los países que integran la OCDE.

El impacto del impuesto progresivo sobre el crecimiento económico a decir de Biswas et al. (2017), tiene que ver con el efecto de dichos impuestos sobre los incentivos de las personas para emplearse, invertir y consumir. Los incentivos son asimétricos y cambian de acuerdo con el nivel de ingreso, por lo tanto, Biswas et al. (2017) estudian el efecto de la reducción de la desigualdad de los hogares sobre el crecimiento, haciendo una distinción entre hogares de ingresos bajos y medianos y hogares de ingresos altos y medianos. La reducción de la pobreza mejora el crecimiento, pero reducir la brecha entre los ingresos medianos y altos reduce el crecimiento. La diferencia sobre el impacto que se genera en el crecimiento se debe a que la reducción de la pobreza incrementa la oferta de mano de obra femenina, mejora el desempeño de las pequeñas empresas, además de incrementar el consumo, pero en el segundo caso se reduce la oferta de trabajo femenino, así como el crecimiento de las pequeñas empresas y la creación de empleos. 
Por su parte Rick et al. (2018) analizan el efecto del impuesto progresivo sobre la motivación en el trabajo, de acuerdo con la evidencia experimental establecen que el resultado dependerá de la valoración y alineación que tengan las personas sobre la distribución y la intervención del gobierno. Para aquellos que se encuentran identificados con estos elementos los impuestos serán una fuente de motivación y tendrá impactos positivos sobre los niveles de productividad, pero aquellos que no estén identificados con dichos elementos pueden sentirse desmotivados para trabajar.

Un planteamiento a favor de los impuestos progresivos es la moral tributaria, de acuerdo con Doerrenberg y Peichl (2013), la moral tributaria de una persona se incrementa en la medida que el sistema tributario se hace más progresivo y el efecto se va diluyendo en la medida que el ingreso de dicha persona es menor; en una sociedad donde la moral tributaria va en ascenso la evasión fiscal será menor por lo que se puede inferir que a mayor progresividad menor evasión fiscal. Bajo una tesis similar Castañeda (2017), aporta evidencia para algunos países de América Latina sobre el desincentivo que tienen las personas de pagar impuestos en la medida que perciben que sus sistemas tributarios son más inequitativos.

Desde el ámbito de la sociología, Bradley (2018) trata de establecer el impacto que han tenidos los impuestos personales sobre la distribución del ingreso en los últimos años en los Estados Unidos, demostrando que la desgravación fiscal ha generado una concentración de beneficios en hombres blancos de clase alta, lo cual en lugar de disminuir las desigualdades existentes las ha exacerbado mermando con ello el poder redistributivo que tienen los sistemas tributarios progresivos. A diferencia de Bradley, Splinter (2018) menciona que son las modificaciones en la política fiscal de los Estados Unidos lo que ha generado una mayor progresividad en el impuesto sobre la renta individual.

Por último, la literatura al respecto de los impuestos progresivos se deriva en diferentes direcciones como es el establecimiento de impuestos con mayor impacto en la distribución del ingreso y la riqueza tal el caso del impuesto sobre herencias (Piketty y Saez, 2013; Pedersen, 2018), los impuestos sobre la renta altamente progresivos que graven la riqueza (Slemrod, 1998; Piketty y Qian, 2009; Scheve y Stasavage, 2016). El papel que juegan los impuestos progresivos como estabilizadores automáticos (Dromel y Pintus, 2004 y 2008; Krajewski y Pilat, 2017), además de nuevas formas de medir el efecto que tienen los impuestos progresivos sobre la distribución del ingreso (Du y Zhong, 2018). 


\section{Impuestos y distribución del ingreso en México}

En México existen pocos temas en los que la gran mayoría de los economistas pueden estar de acuerdo, uno de ellos es el pobre desempeño que tiene el país en materia de recaudación. No importa qué criterio o comparativa se use, el resultado siempre apunta en la misma dirección. La Figura 1, ofrece información sobre la recaudación en relación con el PIB para los años de 2008 a 2016 del país, así como el promedio de un grupo importante de países a lo largo del mundo para los cuales reporta información el Banco Mundial. Hasta el año 2012 parecía que la recaudación había caído en una trampa que le impedía superar la barrera del 10\%.

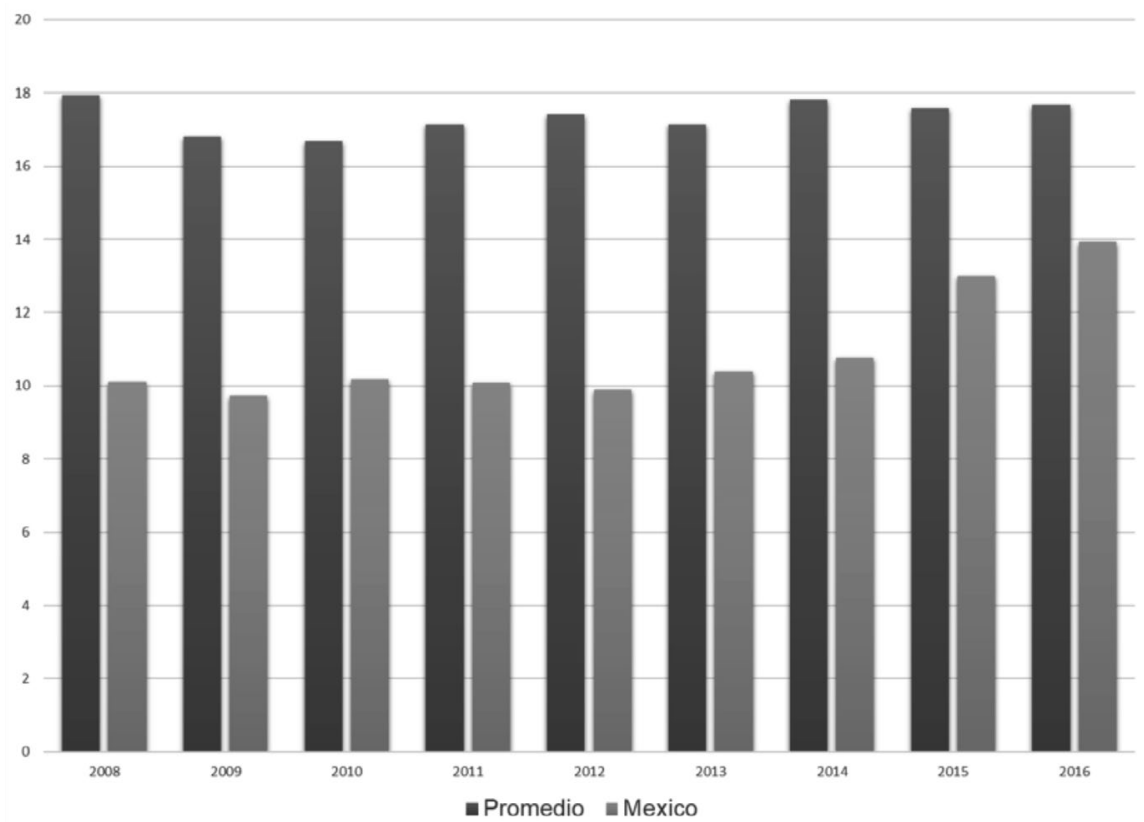

Figura. 1. Recaudación tributaria en relación con el PIB (2008-2016) ${ }^{1}$ Fuente: Elaboración propia con datos del Banco Mundial

La estructura tributaria en México ha tenido cambios mínimos que no pueden ser considerados como una reforma tributaria. En 2007 se adicionaron nuevos impuestos que fueron derogados en el año 2014, en 2010 se incrementaron las tasas marginales de los tres principales gravámenes, en 2012 se implementó el esquema de pagos referenciados lo que permitió iniciar

\footnotetext{
${ }^{1}$ El promedio corresponde a países de todos los niveles de ingreso y su numero cambia en cada año, ya que se consideran en el promedio a todos aquellos que presentaron información y su número puede ser observado en la figura 2.
} 
con la consolidación de un padrón de contribuyentes, en 2014 se hizo obligatorio el esquema de pagos referenciados para personas físicas y morales, con lo cual se avanzó en la reducción de la evasión fiscal y amplió el padrón de contribuyentes (Ramírez 2007, 2012, 2013, 2019).

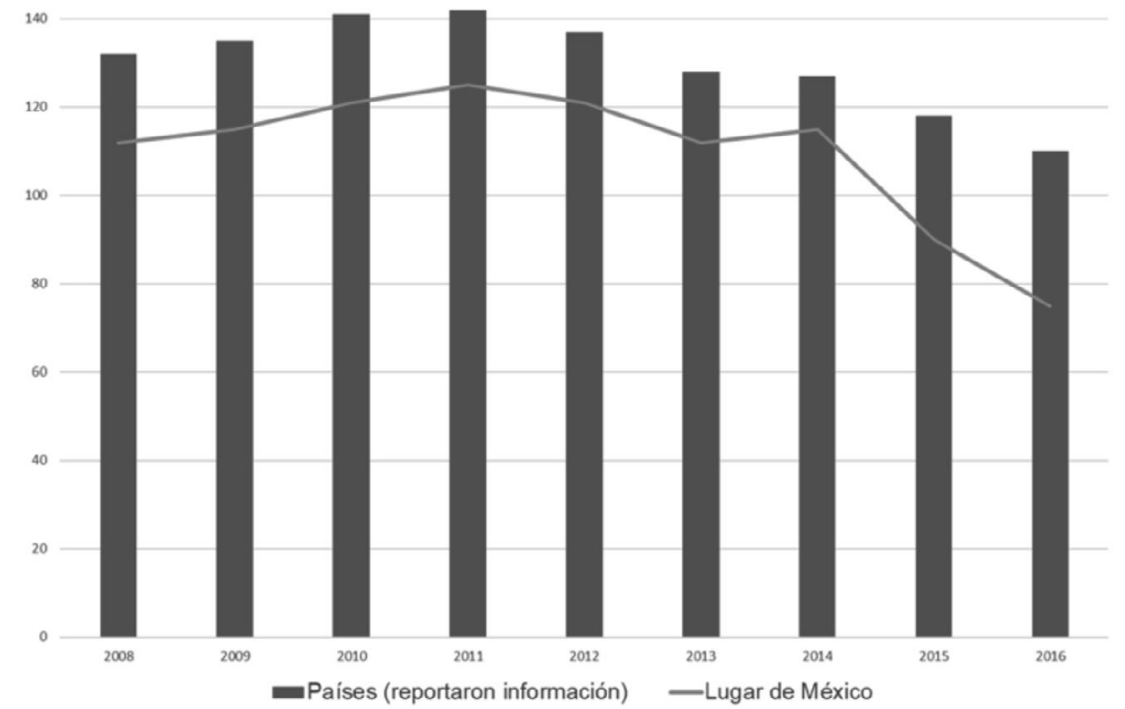

Figura. 2. Número de países que presentaron información sobre su recaudación y la posición que ocupaba México (2008-2016) Fuente: Elaboración propia con datos del Banco Mundial

La obligatoriedad de los pagos referenciados a diferencia de las otras medidas llevadas a cabo tuvo la virtud de romper con la trampa del 10\%, como se puede apreciar en la Figura 1. Para dar una idea sobre el avance que tuvo el país en relación con otras economías en la Figura 2 se presenta en las barras, la cantidad de países que presentaron información de su recaudación en relación con el PIB y en la línea, el lugar que ocupaba México de acuerdo con su recaudación. Como puede apreciarse, en 2012 de 137 países México ocupaba el lugar 121, en 2016 de 110 países ocupaba el lugar 75.

En México la recaudación principal se concentra en dos gravámenes que son el ISR (Impuesto sobre la Renta) y el IVA (Impuesto al Valor Agregado), en promedio en los últimos 36 años concentran poco menos del $85 \%$ de todos los ingresos tributarios, teniendo una inherencia mayor el primero con poco más del 50\% y el IVA el resto. El IVA siendo un im- 
puesto indirecto se configura en la teoría y en la práctica como regresivo, por lo cual se trata de mermar su efecto negativo mediante una diferenciación de tasas para ciertos consumos como es el caso de la tasa cero a medicinas y alimentos. Sin embargo, dicha medida ha sido cuestionada por diferentes personas argumentando que con ello se hace más regresivo el impuesto, propicia elusión y evasión fiscal, además de ampliar los gastos fiscales derivados de la medida. De acuerdo con Tanzi (2003), el IVA es un impuesto que sirve para recaudar y si se va a usar debe mantenerse lo más general posible para que logre su propósito ${ }^{2}$, a tal respecto Malo y Vélez (2012), así como Ramírez (2013) han realizado algunas estimaciones sobre la ampliación de la regresividad del IVA.

En cuanto al ISR el impuesto se maneja en dos grandes modalidades, personas físicas y personas morales. En el segundo caso se establece una tasa marginal general para todos con algunas salvedades, mientras que en el primer caso se fijan tarifas diferenciadas sobre distintos tramos de ingreso, la idea es que a medida que se incrementa el ingreso las personas contribuyan más que proporcionalmente con el Estado, generando con ello una redistribución del ingreso. En el próximo apartado se realizará la estimación al respecto de la progresividad del ISRPF, pero no sin antes describir qué pasa en materia de distribución de ingresos en el país ${ }^{3}$.

México, de acuerdo con el Coeficiente de Gini ${ }^{4}$ antes de impuestos y transferencias correspondiente al año 2013, se encuentra entre los primeros 15 países de la OCDE con la mejor distribución. Sin embargo, si se valora con el Coeficiente Gini después de ingresos y transferencias se ubica entre los de menor distribución solamente superado por Chile, lo cual es una evidencia respecto de la capacidad o márgenes de maniobra que tiene el gobierno para mejorar el bienestar general de la sociedad; dentro de los problemas más relevantes que observa el FMI (Fondo Monetario Internacional) (2017) para México es la persistencia de la pobreza y desigualdad, así como sus bajos niveles de recaudación.

La pobreza en México de acuerdo con el FMI aflige a más del $40 \%$ de la población, mientras que el Gini persistentemente se encuentra en valores cercanos al 0.5, mientras que los países de la OCDE se mantienen en promedio en valores de 0.3. La recaudación aun cuando se ha mejorado sigue siendo baja y eso entre otras cosas se debe a que muchas empresas no pagan impuestos, ya sea porque se encuentran en la informalidad o bien porque tienen el poder económico y político para hacerlo (OXFAM, 2015).

\footnotetext{
${ }^{2}$ Mantener la recaudación a ciertos niveles hace necesario acompañar las estructuras tributarias con impuestos indirectos como lo mencionan Barreix y Roca (2007) para el caso de Uruguay país en el cual la mitad de su carga tributaria en 2005 se originaba por dichos impuestos.

${ }^{3}$ Este sistema se popularizó de acuerdo con Barreix y Roca (2007) como el sistema dual nórdico que grava las rentas del capital con tasas proporcionales y las rentas del trabajo con tasas progresivas.

${ }^{4}$ Medida para estimar la distribución desigual, normalmente es utilizada para medir la desigualdad de los ingresos dentro de un país.
} 


\section{Análisis de la progresividad del ISRPF}

En este apartado se analizará la distribución del ingreso de personas físicas para los años de 2010 a 2015, además de estimar la progresividad del ISRPF y su efecto distributivo. Para ello se utilizarán las bases de datos sobre la declaración anual de dicho impuesto que en cumplimiento del Artículo décimo noveno transitorio de la Ley de Ingresos de la Federación 2017, puso a disposición el SAT.

\section{Datos}

Los datos utilizados en el análisis se obtuvieron de la base de datos, que a partir del 20 de diciembre del 2017 publicó el SAT, en la que se concentran las declaraciones fiscales anuales de personas físicas y morales, la cual abarca los ejercicios fiscales anuales desde el año 2010 hasta el 2015. Estas bases de datos contienen todas las declaraciones fiscales de contribuyentes del año correspondiente, pero tienen un carácter anonimizado, es decir, no muestran información personal de los declarantes, por lo cual no se pueden vincular las cifras de ingreso y pago de impuestos con ningún contribuyente.

De acuerdo con el SAT (2018) las bases de datos se presentan a nivel de micro dato, son confidenciales y respetan el principio de autodeterminación, lo cual implica que se cuenta con la información de todas las declaraciones realizadas de cada contribuyente, pero no se puede establecer de forma razonable su identidad, además que se respetan los datos plasmados por el contribuyente, independientemente de que puedan resultar incongruentes.

Para anonimizar los datos el SAT les adicionó a las variables choques aleatorios con la finalidad de eliminar la relación entre contribuyente y los datos, generando un proceso de ruido que presentan una distribución normal con media cero y desviación estándar, por lo cual los datos correspondientes a cada declaración no ofrecen la posibilidad de establecer una relación entre ellas, pero no se alteran las relaciones funcionales y estadísticas a nivel agregado. De manera adicional el SAT, tomando en cuenta la anonimización, realizó una depuración de datos atípicos tomando como base la variable "total de ingresos acumulables".

La información presentada por el SAT corresponde a tres grupos de contribuyentes: Personas Morales bajo el régimen general, Personas Físicas obligadas y no obligadas a presentar declaración anual y la declaración informativa múltiple de sueldos y salarios.

La población objeto de estudio en el presente documento es la de los contribuyentes clasificados como personas físicas obligadas y no obligadas, para los ejercicios fiscales del 2010 a 2015, periodo con información disponible. Las personas físicas obligadas a presentar 
declaración anual se describen en el artículo 117, fracción III de la Ley del Impuesto Sobre la Renta (LISR) vigente para los años de 2010 a 2013 y artículo 98 fracción III de la nueva LISR, vigente para los años de 2014 y 2015. En general se puede mencionar que los contribuyentes están obligados a declarar cuando hayan obtenido ingresos por los siguientes conceptos: prestar servicios profesionales (honorarios); rentar bienes inmuebles; realizar actividades empresariales (comerciales, industriales, agrícolas, ganaderas, silvícolas, de pesca, y de autotransporte), excepto los que tributen en el Régimen de Incorporación Fiscal; enajenar bienes; adquirir bienes; percibir salarios; recibir intereses. Además de otros ingresos relacionados con: las deudas condonadas por el acreedor o pagadas por otra persona, por inversiones en el extranjero, por intereses moratorios, y/o por penas convencionales, etc. (SAT 2018).

De acuerdo con el informe tributario y de gestión para el cuarto trimestre de 2015 presentado por el SAT (2015a), en el año 2010 el padrón de contribuyentes activos se integraba por 33.5 millones de contribuyentes activos cifra que en 2015 alcanzó los 51.6 millones, de los cuales 3.5\% correspondían a Personas Morales, $38.6 \%$ a Personas Físicas y $57.9 \%$ a Asalariados.

\section{Análisis descriptivo}

De acuerdo con el Reporte anual 2015 y Retos 2016 presentado por el SAT (2015b) en 2015 el número de declaraciones presentadas fue de 5.4 millones, sin embargo, en la base de datos anonimizada se presentan tan sólo 4.7 millones de registros correspondientes a igual número de declaraciones, lo cual puede ser explicado por la depuración comentada anteriormente, en cada uno de los seis años analizados las cifras tienen esa particularidad, como se puede apreciar en el Tabla 1.

De la base de datos compuesta por 45 variables, dos particularmente son relevantes para el presente estudio y corresponden al "Total de Ingresos Acumulables" (TIA) y el "Impuestos Sobre la Renta Causado" (ISRC), con base en ellas se pretende establecer la distribución del ingreso y el efecto distributivo que tiene el impuesto. Para tal propósito se realizó una nueva depuración de las series eliminando aquellos registros en los que la TIA era cero o no contenía información o bien en los casos en que no se registró impuesto causado. Una vez realizada dicha depuración de la totalidad de las declaraciones se analizó para el año 2010 tan sólo el 62\%, porcentaje que fue aumentando a lo largo del periodo llegando al $84 \%$ para el año 2015, como se reporta en la Tabla 1. Es importante mencionar que dada la eliminación de los registros se tuvieron cambios marginales en los resultados, aun cuando las tendencias se mantuvieron en lo general. 
Tabla 1

Número de declaraciones anuales, registros totales y analizados

\begin{tabular}{lccc}
\hline Año & Declaraciones anuales & Registros totales & Registros Analizados \\
\hline 2010 & $3,121,383$ & $3,084,581$ & $1,907,495$ \\
2011 & $3,217,616$ & $3,397,961$ & $2,043,568$ \\
2012 & $3,584,788$ & $3,678,138$ & $2,360,490$ \\
2013 & $4,086,990$ & $4,156,047$ & $3,014,340$ \\
2014 & $4,703,885$ & $4,497,340$ & $3,462,081$ \\
2015 & $5,433,502$ & $4,651,488$ & $3,907,787$ \\
\hline
\end{tabular}

Fuente: Elaboración propia con datos del SAT

Los ingresos acumulables de este segmento de contribuyentes representaban en 2010 alrededor del $6.6 \%$ del PIB y se fueron incrementando a lo largo del periodo para llegar a poco más de 9\% en 2015 (Figura 3). ¿Qué es lo que explica el comportamiento de la TIA? Para algunos años se puede explicar por el dinamismo de la economía, pero para todo el periodo la explicación tiene que ver con el incremento de padrón de contribuyentes, que se hace evidente por el aumento de las declaraciones presentadas y por supuesto de los registros analizados en el presente trabajo, de 2010 a 2015 los registros analizados se incrementaron en 105\%, mientras que la TIA en el periodo lo hizo cerca del $60 \%$ y el PIB cerca del 16\%. Para el año 2013 se da un incremento importante en los registros analizados que es posible asociar con un programa de regularización de adeudos fiscales denominado "ponte al corriente".

En el periodo de estudio las tarifas sobre las que se hace el cobro del impuesto tuvieron cambios tanto cuantitativos como cualitativos, de 2010 a 2012 la LISR establecía una tarifa con una tasa marginal máxima de $30 \%$ a los ingresos que excedieran los $\$ 392,842.97$, la tarifa contemplaba 8 niveles de ingreso. Para el año 2013 se modificó la tarifa estableciendo una tasa marginal máxima del $29 \%$ y ajustando las dos tasas excedentes previas, así como sus correspondientes cuotas fijas, dicha modificación se publicó el 11 de diciembre de 2013 en el Diario Oficial de la Federación a través de la nueva LISR, abrogando la anterior publicada el 1ro de enero de 2002. 


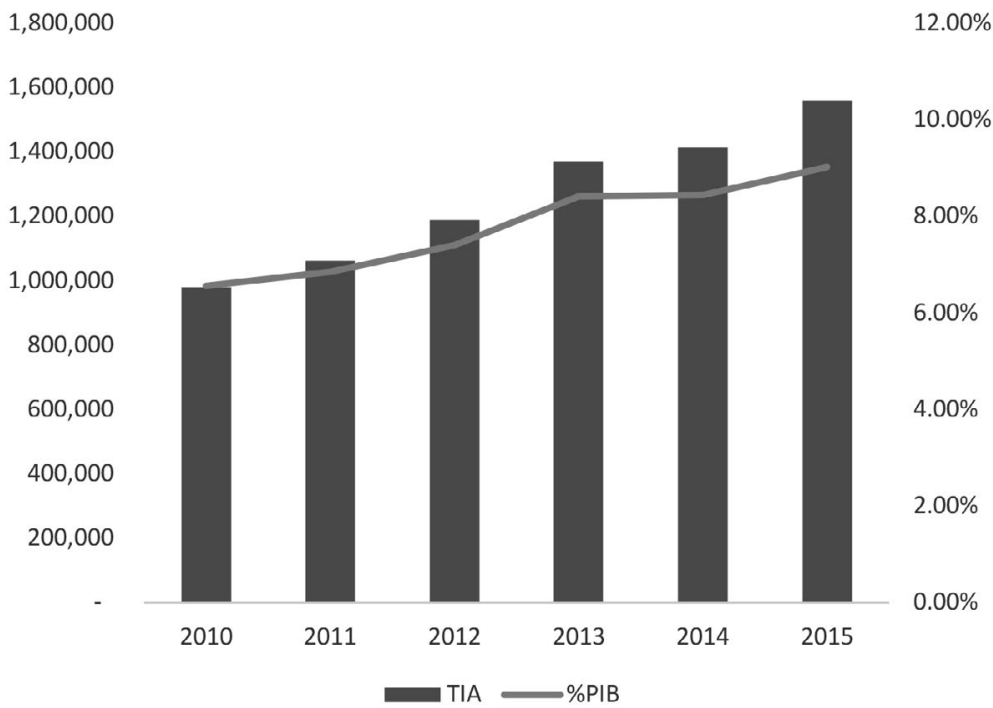

Figura. 3. Ingresos totales acumulables e ingresos tributarios (a precios de 2013, en millones de pesos y \%PIB) Fuente: Elaboración propia con datos del SAT

400,000 $26.00 \%$

350,000

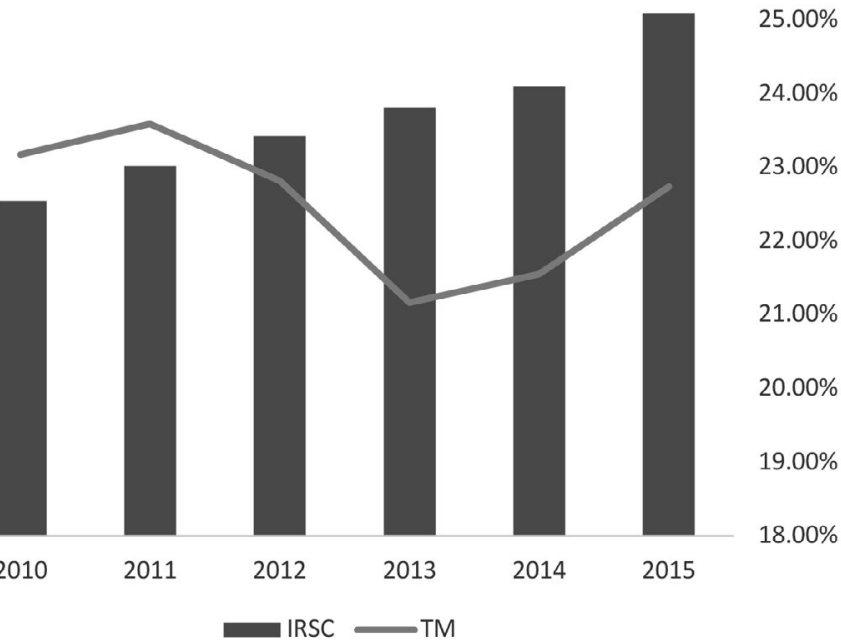

Figura. 4. Impuesto sobre la renta causado y la tasa media (a precios de 2013, en millones de pesos)

Fuente: Elaboración propia con datos del SAT 
La tarifa establecida con la nueva LISR toma la tarifa de 2010-2012 y agrega tres niveles de ingresos adicionales con las respectivas tasas marginales, para el noveno nivel de ingreso se establece un límite inferior de $\$ 750,000.01$ y superior de $\$ 1,000,000$ con una tasa marginal de $32 \%$ para el ingreso excedente del límite inferior y una cuota fija de $180,850.82$, el siguiente nivel de ingreso va de $\$ 1,000,000.01$ a 3,000,000 con una tasa marginal excedente de $34 \%$ y una cuota fija de $\$ 260,850.81$, el último nivel de ingreso va de $\$ 3,000,000.01$ en adelante con una tasa marginal excedente de $35 \%$ y una cuota fija de $\$ 940,850.81$. Los cambios en las tarifas tuvieron su efecto en las tasas medias que pasaron de $23.59 \%$ en 2012 a $22.81 \%$ en 2013, con la nueva LISR la tasa media se mejoró (Figura 4).

De acuerdo con los informes trimestrales de la Secretaría de Hacienda y Crédito Público (SHCP), la explicación del cambio en el ISRC de 2010 a 2012 se debió principalmente al dinamismo de la actividad económica, en términos reales la tasa de crecimiento en esos años estuvo alrededor de $3.65 \%$, las más altas del periodo de estudio. La mejoría de la recaudación en 2013 como ya se había comentado se debió relativamente al programa "ponte al corriente" además de menores compensaciones registradas por el impuesto, esto ayudó a mejorar la recaudación incluso a pesar de la desaceleración económica de 2013. En su reporte anual el SAT menciona que la comparación directa de la recaudación observada en el ISR entre 2013 y los años anteriores es inadecuada en virtud del nuevo manejo sobre compensaciones que se tuvo a partir de ese año. Por otro lado, a medida que se da la vinculación electrónica en el sistema fiscal también se ha mejorado el nivel de recaudación, como se puede apreciar en la Figura 4.

En materia de concentración del ingreso ¿Qué es lo que ocurría en este estrato de la población? Antes del efecto de los impuestos de acuerdo con la TIA, el 10\% de la población con mejores ingresos concentraba el 50\%, mientras que el 50\% de la población de menores ingresos tan sólo se apropiaba del 9\%, quedando el resto en la población de ingresos medios.

La concentración del ingreso a lo largo del periodo se fue moderando pero en 2015 se revirtió la tendencia, no obstante, se avanzó en reducir la concentración ya que en ese año el $10 \%$ de la población de mejor ingreso concentraba el $43 \%, 7$ puntos porcentuales menos que en 2010 , el $50 \%$ de la población se apoderó de $5 \%$ más del ingreso en comparación con el 2010, mientras que el 40\% de ingresos medios lo hizo en un 2\% (Figura 5).

A partir de la figura 5 es posible observar que la actividad económica sin el aparente efecto de los impuestos ha reducido la concentración del ingreso, pero es importante no perder de vista que se han dado cambios en la estructura del impuesto y que por lo tanto eso condiciona el análisis a dos comportamientos; por un lado 2010-2012 y por el otro 2013-2015. En los primeros tres años el proceso es más lento que en los siguientes, lo que hace pensar en un 
efecto indirecto de los impuestos sobre los contribuyentes tratando de reducir sus cargas impositivas, lo cual podría ser también una explicación del incremento de las personas físicas en cerca de 5.6 millones de 2013 a 2015.

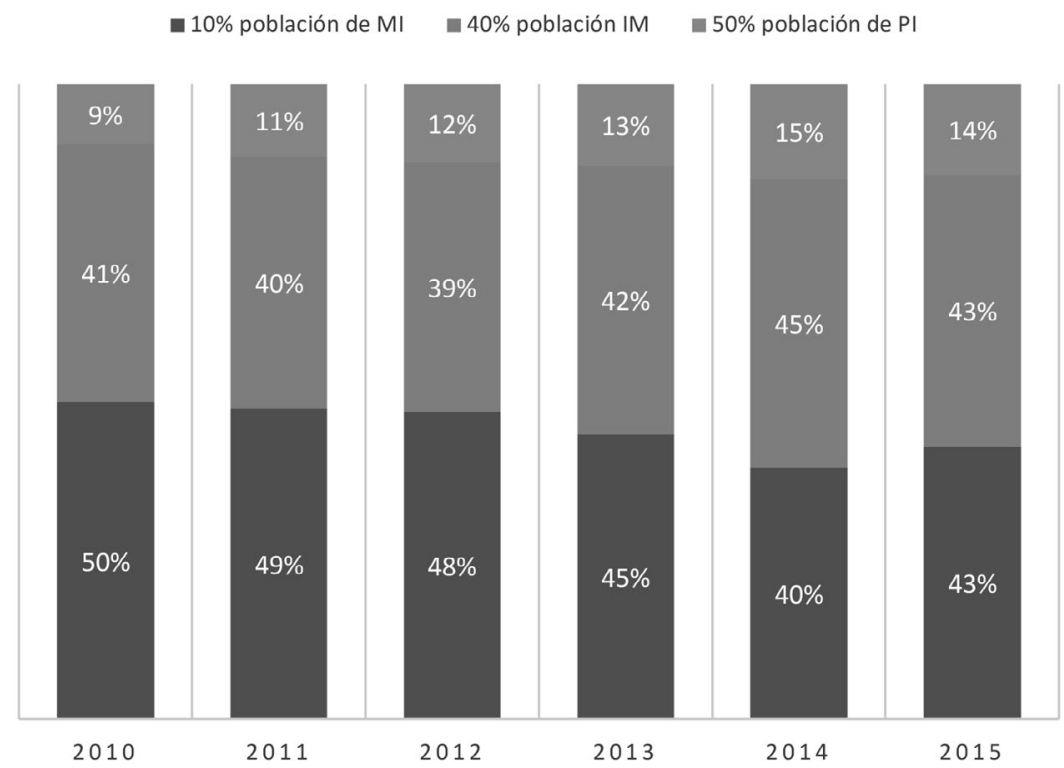

Figura. 5. Concentración del ingreso antes de impuesto 2010-2015 Fuente: Elaboración propia con datos del SAT5

En la Figura 6 se presenta la concentración del ingreso después del impuesto, en el año 2010 la diferencia de la situación con impuesto y sin impuesto para el 10\% de la población de mejores ingresos significaba una reducción en la concentración alrededor de 2.7 puntos porcentuales que se distribuyeron 0.9 en el $50 \%$ de menores ingresos y el resto en el porcentaje de la población sobrante. En 2012 la situación considerando el impuesto redujo en 2.9 puntos porcentuales la concentración del $10 \%$ de la población con mejores ingresos, mejorando la participación del $50 \%$ de la población en 1.3 puntos porcentuales y 1.6 puntos porcentuales para el $40 \%$ de la población de ingresos medios.

En el periodo de 2013 a 2015, después del impuesto se logró un mayor impacto en la participación del 10\% de la población de mejores ingresos y una mejor participación del 50\% de la población de menores ingresos. Dado lo anterior se podría inferir que el impuesto ha

\footnotetext{
${ }^{5} \mathrm{MI}$ indica el $10 \%$ de la población de mejores ingresos, IM corresponde al $40 \%$ de la población de ingresos medios y PI se refiere al $50 \%$ de la población con ingresos más bajos (peores ingresos).
} 
tenido cierta capacidad de redistribución por lo menos en la población y los años de estudio, aun cuando siguen siendo cambios marginales.

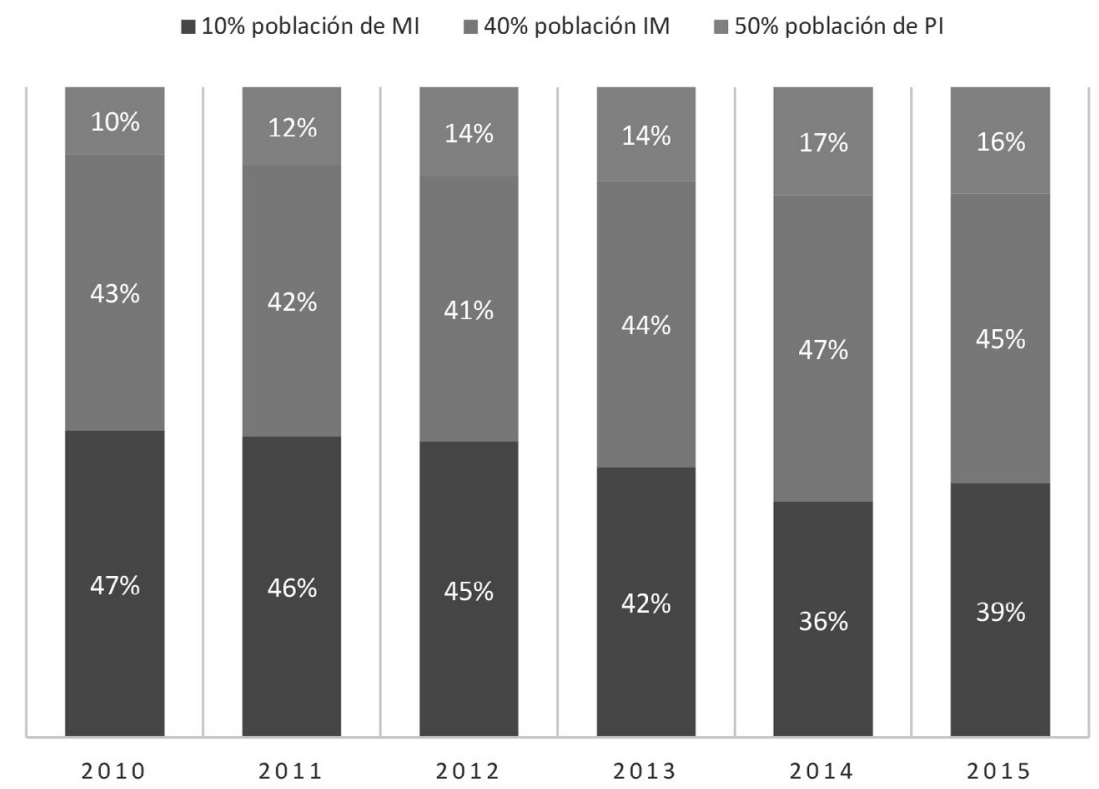

Figura. 6. Concentración del ingreso después de impuesto 2010-2015

Fuente: Elaboración propia con datos del SAT

Descomposición del ingreso en deciles y su concentración

La Tabla 2 presenta la TIA promedio a precios de 2013, para cada uno de los deciles de ingreso de acuerdo con los años de estudio, es interesante observar que en 2010 el ingreso promedio del decil 10 representaba 405 veces el ingreso del primer decil, y dadas las tendencias al alza en el segundo caso y a la baja en el primero, para 2015 el número de veces que el décimo decil fue mayor al primero fue tan sólo de 69 veces, sin que ello sea directamente a causa del efecto impositivo. 
Tabla 2

Total de ingresos acumulables promedios 2010-2015 (pesos a precios de 2013)

\begin{tabular}{crrrrrr}
\hline Decil & \multicolumn{1}{c}{2010} & \multicolumn{1}{c}{2011} & \multicolumn{1}{c}{2012} & \multicolumn{1}{c}{2013} & \multicolumn{1}{c}{2014} & \multicolumn{1}{c}{2015} \\
\hline 1 & $6,335.07$ & $8,424.54$ & $9,663.37$ & $13,500.75$ & $24,058.21$ & $25,006.77$ \\
2 & $26,109.17$ & $37,678.64$ & $41,702.71$ & $61,610.35$ & $75,461.81$ & $73,472.59$ \\
3 & $73,575.08$ & $105,613.49$ & $124,457.68$ & $117,539.20$ & $119,640.60$ & $114,709.50$ \\
4 & $150,041.38$ & $173,387.71$ & $191,527.72$ & $165,417.00$ & $169,382.70$ & $154,575.16$ \\
5 & $223,957.95$ & $263,351.89$ & $252,473.07$ & $220,702.40$ & $221,162.58$ & $198,393.24$ \\
6 & $357,303.29$ & $357,231.13$ & $337,816.29$ & $305,407.50$ & $297,220.15$ & $266,109.53$ \\
7 & $449,625.81$ & $444,824.98$ & $419,929.64$ & $412,382.20$ & $395,706.21$ & $359,481.99$ \\
8 & $554,219.08$ & $547,411.91$ & $503,901.29$ & $517,800.70$ & $495,635.64$ & $457,635.05$ \\
9 & $735,899.35$ & $723,905.65$ & $718,267.08$ & $694,989.30$ & $670,731.16$ & $630,618.26$ \\
10 & $2,567,301.50$ & $2,540,800.89$ & $2,436,852.37$ & $2,041,307.00$ & $1,619,818.43$ & $1,714,276.00$ \\
\hline
\end{tabular}

Fuente: Elaboración propia con datos del SAT

En la Tabla 3 se muestra la renta tributaria promedio a precios de 2013, concepto que se refiere al impuesto causado por los contribuyentes. Comparando los extremos, es decir, el decil 10 y el 1, es posible percibir que la brecha entre ellos es amplia siendo mucho mayor al observado por la TIA promedio, en 2010 la renta tributaria promedio del decil 10 es 3,437 veces mayor que la del decil 1, mientras que en 2015 la relación fue de 374 veces.

Tabla 3

Renta tributaria promedio 2010-2015 (pesos a precios de 2013)

\begin{tabular}{rrrrrrr}
\hline & 2010 & \multicolumn{1}{c}{2011} & 2012 & \multicolumn{1}{c}{2013} & \multicolumn{1}{c}{2014} & \multicolumn{1}{c}{2015} \\
\hline 1 & 204.71 & 378.88 & 443.49 & 644.41 & $1,337.99$ & $1,349.05$ \\
2 & $1,399.82$ & $5,286.27$ & $3,103.66$ & $3,547.97$ & $4,564.39$ & $4,507.46$ \\
3 & $9,670.49$ & $17,763.47$ & $21,878.54$ & $9,749.65$ & $11,528.94$ & $10,877.15$ \\
4 & $31,144.39$ & $36,026.82$ & $26,019.85$ & $17,777.63$ & $31,308.25$ & $18,561.37$ \\
5 & $32,948.77$ & $50,891.86$ & $37,671.65$ & $28,469.32$ & $29,711.60$ & $27,568.42$ \\
6 & $56,427.43$ & $61,010.38$ & $57,538.71$ & $45,839.61$ & $45,652.77$ & $42,330.03$ \\
7 & $80,811.06$ & $81,209.74$ & $79,057.09$ & $69,517.76$ & $67,607.98$ & $64,581.86$ \\
8 & $111,615.07$ & $113,214.33$ & $103,375.06$ & $95,301.14$ & $92,016.63$ & $91,545.37$ \\
9 & $164,303.18$ & $162,057.79$ & $151,218.16$ & $144,974.00$ & $141,019.60$ & $141,837.72$ \\
10 & $703,633.08$ & $699,496.33$ & $668,715.75$ & $547,383.20$ & $456,542.33$ & $505,000.00$ \\
\hline
\end{tabular}

Fuente: Elaboración propia con datos del SAT 
Dado lo anterior es posible suponer, por una parte, que se ha reducido la concentración del ingreso y por otra que el impuesto ha resultado progresivo. Al calcular la tasa media del impuesto para los deciles (Tabla 4) se pueden hacer las siguientes precisiones:

a) Los cambios abruptos que se dan en las tasas medias del decil 4 y 5 obedecen a cambios en la composición de las tarifas que no atienden a la composición de los deciles de ingreso.

b) Los cambios mínimos que se han presentado en las tasas medias de los deciles 9 y 10 ejemplifican la dificultad que se tiene para generar una mayor distribución en los deciles con mejor ingreso.

c) En el año 2015 la tasa media para los diferentes deciles denota un comportamiento ordenado en el cual la tasa media se incrementa en la medida que se incrementa el ingreso, lo que permite pensar en un patrón de progresividad.

Tabla 4

Tasa Media de Impuesto 2010-2015 (en \%)

\begin{tabular}{ccccccc}
\hline & 2010 & 2011 & 2012 & 2013 & 2014 & 2015 \\
\hline 1 & 3.23 & 4.50 & 4.59 & 4.77 & 5.56 & 5.39 \\
2 & 5.36 & 14.03 & 7.44 & 5.76 & 6.05 & 6.13 \\
3 & 13.14 & 16.82 & 17.58 & 8.29 & 9.64 & 9.48 \\
4 & 20.76 & 20.78 & 13.59 & 10.75 & 18.48 & 12.01 \\
5 & 14.71 & 19.32 & 14.92 & 12.90 & 13.43 & 13.90 \\
6 & 15.79 & 17.08 & 17.03 & 15.01 & 15.36 & 15.91 \\
7 & 17.97 & 18.26 & 18.83 & 16.86 & 17.09 & 17.97 \\
8 & 20.14 & 20.68 & 20.51 & 18.40 & 18.57 & 20.00 \\
9 & 22.33 & 22.39 & 21.05 & 20.86 & 21.02 & 22.49 \\
10 & 27.41 & 27.53 & 27.44 & 26.82 & 28.18 & 29.46 \\
\hline
\end{tabular}

Fuente: Elaboración propia con datos del SAT

El coeficiente de Gini es coincidente con los datos anteriores denotando una amplia concentración del ingreso que se redujo en el periodo, pero que está lejos incluso de la situación nacional que de acuerdo con datos del Banco Mundial fue de 0.453, 0.454 y 0.458 para los años de 2010, 2012 y 2014 respectivamente, mientras que para esos años los datos del estrato de la población de estudio fueron $0.638,0.607$ y $0.534^{6}$. En los años de 2013 a 2015

\footnotetext{
${ }^{6}$ La reducción de la desigualdad de ingresos no fue privativa de México, de acuerdo con Amarante y Colacce (2018) la región de América Latina tuvo una tendencia favorable en la reducción de la desigualdad en el periodo de 2002 a 2014, proceso que se dio gracias a factores a nivel general como el incremento del precio de los productos básicos, que mejoró la dinámica del mercado laboral y con ello el empleo de trabajadores no calificados y los salarios. A nivel particular se han mejorado factores institucionales en materia laboral e instrumentado políticas redistributivas.
} 
aun cuando de forma limitada se mejoró, la condición del coeficiente de Gini a favor de una menor concentración del ingreso sigue siendo mínima sobre todo para el tipo de impuesto del que se trata (Figura 7).

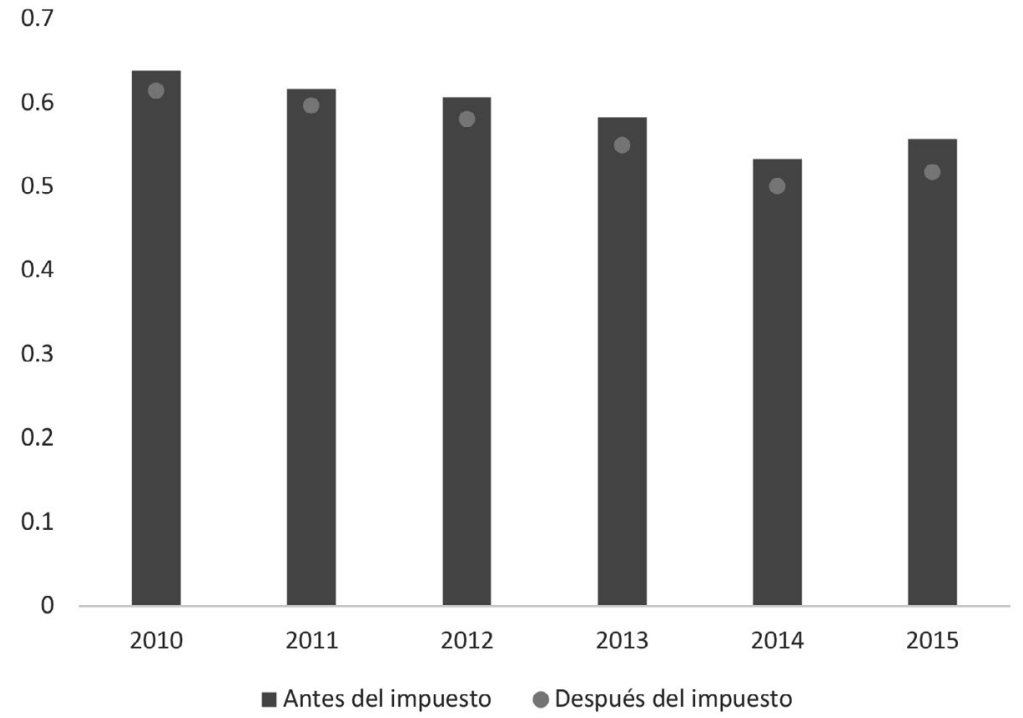

Figura. 7. Coeficiente de GINI antes y después de impuesto 2010-2015 Fuente: Elaboración propia con datos del SAT

Al descomponer el coeficiente de Gini para cada decil, la más amplia concentración del ingreso se encuentra en los deciles extremos y particularmente es mayor en el décimo decil correspondiente al $10 \%$ de la población con mejores ingresos, mientras que el séptimo decil es el que presenta la menor concentración. En los años de 2010 a 2012 el impuesto tuvo una mínima incidencia en modificar esa situación. Sin embargo, es importante denotar que en los años 2013 a 2015 el impuesto tuvo incidencia favorable en reducir la concentración en el décimo decil, pero su impacto en el último percentil es ínfimo.

De acuerdo con los datos en 2010, más del $21 \%$ del ingreso se concentraba en el $1 \%$ de los contribuyentes de mejor condición económica, situación similar a la de los dos años siguientes, derivado de los cambios realizados en 2013 el ingreso concentrado en el último percentil fue menor al 18\% y para 2015 ya con la nueva LISR menor del 15\%. En la Figura 8 se presenta el promedio del coeficiente de Gini para el periodo de 2010-2012 y 2013-2015, 
agrupando los deciles del 1al 9, décimo decil y el último percentil, la figura ofrece una perspectiva interesante sobre dos aspectos:

Deciles 1-9 Decil $10 \quad$ Ultimo percentil

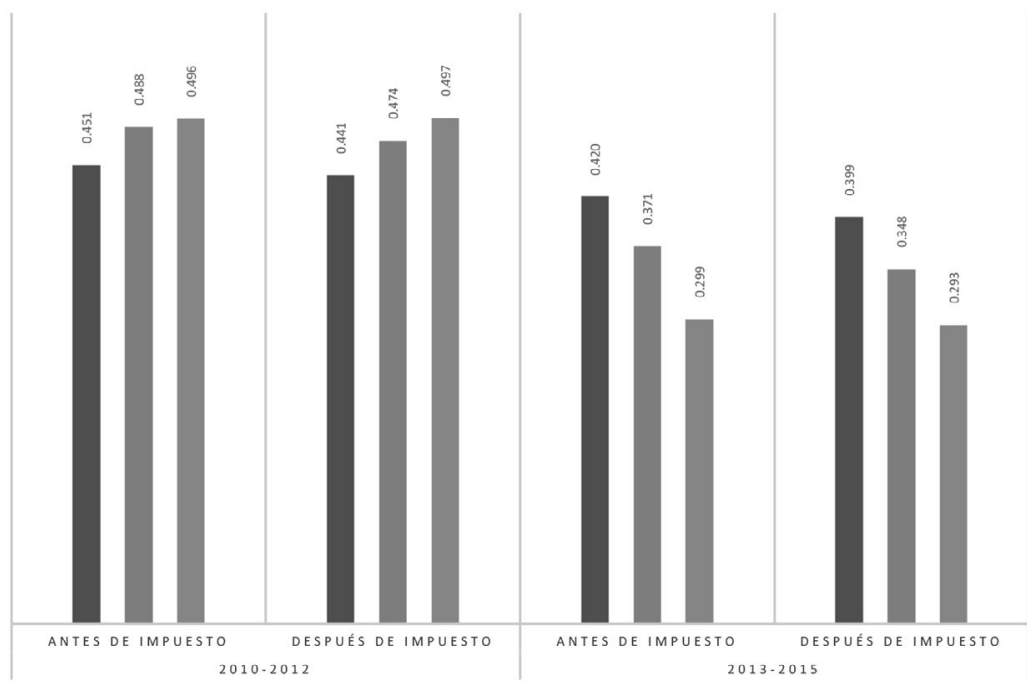

Figura. 8. Promedios del Coeficiente de GINI antes y después de impuesto para diferentes estratos de ingreso (2010-2012, 2013-2015)

Fuente: Elaboración propia con datos del SAT

a) Un cambio en la concentración del ingreso del primer grupo de años respecto al segundo, lo que indica que las modificaciones realizadas en el impuesto han seguido una dirección correcta en la atenuación de dicha concentración, aun cuando falta una mayor incidencia.

b) El efecto sobre la atenuación de la concentración para el periodo 2013-2015 se da tanto en el $90 \%$ de los contribuyentes como en el $10 \%$, pero su capacidad es menor para el $1 \%$. Lo que hace necesario pensar en impuestos directos relacionados con las herencias, legados y donaciones para tratar de tener más incidencia en el último percentil.

\section{Análisis de progresividad}

El concepto de progresividad al parecer puede ser simple de entender, relativamente fácil de explicar, pero ambiguo de obtener, dicha ambigüedad de acuerdo con Musgrave y Thin 
(1948) consiste en que el resultado depende de cómo se mide el grado de progresión, para dichos autores una estructura de tasas es progresiva cuando la tasa promedio de un impuesto aumenta al subir la escala de ingresos, mientras que es proporcional cuando la tasa permanece constante y regresiva cuando la tasa promedio se reduce a medida que se incrementa el ingreso.

Musgrave y Thin (1948) exponen cuatro maneras diferentes de obtener el grado de progresividad que se muestran en la Tabla 5, las dos primeras derivadas de los Planteamientos de Pigou, la tercera en relación con la elasticidad de la renta tributaria sobre el ingreso y la última una derivación de la tercera.

Tabla 5

Medidas de progresividad

\begin{tabular}{|c|c|c|c|}
\hline Medida de progresividad & Formula & & Criterio \\
\hline Tasa media de progresión & $\frac{\frac{T_{1}}{Y_{1}}-\frac{T_{0}}{Y_{0}}}{Y_{1}-Y_{0}}$ & $\begin{array}{l}+ \\
0 \\
-\end{array}$ & $\begin{array}{l}\text { Progresivo } \\
\text { Proporcional } \\
\text { Regresivo }\end{array}$ \\
\hline Tasa marginal de progresión & $\frac{\frac{T_{2}-T_{1}}{Y_{2}-Y_{1}}-\frac{T_{1}-T_{0}}{Y_{1}-Y_{0}}}{Y_{1}-Y_{0}}$ & $\begin{array}{l}+ \\
0 \\
-\end{array}$ & $\begin{array}{l}\text { Progresivo } \\
\text { Proporcional } \\
\text { Regresivo }\end{array}$ \\
\hline Progresividad de la obligación & $\frac{T_{1}-T_{0}}{T_{0}} * \frac{Y_{0}}{Y_{1}-Y_{0}}$ & $\begin{array}{l}>1 \\
1 \\
<1\end{array}$ & $\begin{array}{l}\text { Progresivo } \\
\text { Proporcional } \\
\text { Regresivo }\end{array}$ \\
\hline Progresividad del ingreso residual & $\frac{\left(Y_{1}-T_{1}\right)-\left(Y_{0}-T_{0}\right)}{Y_{n}-T_{n}} * \frac{Y_{0}}{Y_{1}-Y_{n}}$ & $\begin{array}{c}<1 \\
1 \\
>1\end{array}$ & $\begin{array}{l}\text { Progresivo } \\
\text { Proporcional } \\
\text { Regresivo } \\
\end{array}$ \\
\hline
\end{tabular}

Donde: $\mathrm{T}_{0}$ es la renta tributaria correspondiente al ingreso $\mathrm{Y}_{0} \mathrm{y}$

$\mathrm{T}_{1}$ es la renta tributaria correspondiente al ingreso $\mathrm{Y}_{1}$, siendo $\mathrm{Y}_{1}>\mathrm{Y}_{0}$

Fuente: Elaboración propia con base en Musgrave y Thin (1948)

Las cuatro medidas establecen distintas relaciones entre el ingreso y la renta tributaria, que presentan como principal distinción el hecho de que a medida que crece el ingreso se va reduciendo la brecha entre el ingreso marginal y el ingreso medio, generando indicadores que conducen a estructuras de impuestos proporcionales, tomando como referencia la progresividad de la obligación (PO) y la progresividad del ingreso residual (PIR). En la Tabla 6 se muestra 
que en general el impuesto mantiene progresividad, teniendo la particularidad de presentar mayor progresividad en los primeros deciles de ingreso, de acuerdo con el PO, en los años de 2010 a 2012 resultaba más progresivo pasar del decil 1 al 2 que hacerlo del decil 9 al 10, para los siguientes años se revierte esa situación al menos para el salto del primer al segundo decil.

Abundando un poco, en 2010 pasar del decil 1 al 2 representaba que por cada peso que se incrementaba el ingreso, la renta tributaria lo hacía en 1.87 pesos, mientras que pasar del decil 9 al 10 por cada peso que se incrementó el ingreso, la renta tributaria lo hizo en 1.32 pesos, a diferencia del año 2015 en el cual es menor la presión tributaria de pasar del decil 1 al 2 que en el caso del decil 9 al 10.

Tabla 6

Progresividad de la obligación (PO) y Progresividad del ingreso residual (PIR)

\begin{tabular}{cccccccccccccc}
\hline & \multicolumn{4}{c}{2010} & \multicolumn{2}{c}{2011} & \multicolumn{2}{c}{2012} & \multicolumn{2}{c}{2013} & \multicolumn{2}{c}{2014} & \multicolumn{2}{c}{2015} \\
\hline Decil & PO & PIR & PO & PIR & PO & PIR & PO & PIR & PO & PIR & PO & PIR \\
\hline 1 & & & & & & & & & & & & \\
2 & 1.87 & 0.97 & 3.73 & 0.87 & 1.81 & 0.96 & 1.26 & 0.99 & 1.13 & 0.99 & 1.21 & 0.99 \\
3 & 3.25 & 0.87 & 1.31 & 0.95 & 3.05 & 0.84 & 1.93 & 0.94 & 2.61 & 0.90 & 2.52 & 0.90 \\
4 & 2.14 & 0.83 & 1.60 & 0.88 & 0.35 & 1.14 & 2.02 & 0.91 & 4.13 & 0.67 & 2.03 & 0.89 \\
5 & 0.12 & 1.23 & 0.80 & 1.05 & 1.41 & 0.94 & 1.80 & 0.90 & -0.17 & 1.26 & 1.71 & 0.90 \\
6 & 1.20 & 0.97 & 0.56 & 1.11 & 1.56 & 0.90 & 1.59 & 0.91 & 1.56 & 0.91 & 1.57 & 0.91 \\
7 & 1.67 & 0.87 & 1.35 & 0.93 & 1.54 & 0.89 & 1.47 & 0.92 & 1.45 & 0.92 & 1.50 & 0.91 \\
8 & 1.64 & 0.86 & 1.71 & 0.84 & 1.54 & 0.88 & 1.45 & 0.91 & 1.43 & 0.91 & 1.53 & 0.88 \\
9 & 1.44 & 0.89 & 1.34 & 0.91 & 1.09 & 0.98 & 1.52 & 0.88 & 1.51 & 0.88 & 1.45 & 0.89 \\
10 & 1.32 & 0.91 & 1.32 & 0.91 & 1.43 & 0.89 & 1.43 & 0.89 & 1.58 & 0.85 & 1.49 & 0.86 \\
\hline
\end{tabular}

Fuente: Elaboración propia.

Respecto al PIR, como se veía en la Tabla 6 cambia su interpretación y será progresivo en los casos en que sea menor a 1 y regresivo cuando sea mayor, siendo proporcional en 1. Tanto el PO como el PIR no tienen diferencias al detectar cambios que se dan de progresivo a regresivo o viceversa, pero su interpretación cambia en relación con qué tan progresivo es el cobro del impuesto. Para muestra en el año 2015, mientras pasar del decil 2 al 3 implica un PO de 2.52 y un PIR de 0.90, pasar del decil 4 al 5 implicaría un PO de 1.71 y un PIR de 0.90 lo cual puede generar una idea errónea al respecto de la progresividad.

En 2010 y 2012 tomando los extremos, el paso del decil 1 al 2 y del 9 al 10 de acuerdo con la medida de progresividad utilizada genera una percepción distinta, tal como se comen- 
taba en líneas anteriores el PO indica una estructura que es más progresiva en el extremo inferior que en el superior, mientras que el PIR indicaría lo contrario. En términos de equidad vertical, lo deseable sería que se mantuviera la medida de progresividad constante a través del cambio del ingreso.

En la tabla 7 se presentan algunas medidas de progresividad agregadas en las cuales se puede observar que independientemente del índice al que se recurra, el ISRPF ha tenido un efecto distributivo, aun cuando su impacto es menor en virtud de la baja recaudación que se obtiene mediante dicho impuesto y su nivel de progresividad que también resulta ligero, tal como se ha registrado por diversos estudios al respecto ${ }^{7}$

Tabla 7

Índices de redistribución, progresividad y equidad

\begin{tabular}{lcccccc}
\hline & 2010 & 2011 & 2012 & 2013 & 2014 & 2015 \\
\hline Gini antes de impuesto & 0.64 & 0.62 & 0.61 & 0.58 & 0.53 & 0.56 \\
Gini después de impuesto & 0.62 & 0.60 & 0.58 & 0.55 & 0.50 & 0.52 \\
Índice de Musgrave-Thin & 1.06 & 1.05 & 1.07 & 1.08 & 1.07 & 1.09 \\
Índice de Progresividad de Suits & 0.12 & 0.10 & 0.13 & 0.17 & 0.17 & 0.18 \\
Índice de Progresividad de Kakwani & 0.08 & 0.07 & 0.09 & 0.12 & 0.12 & 0.14 \\
Índice de Reynolds-Smolensky & 0.02 & 0.02 & 0.03 & 0.03 & 0.03 & 0.04 \\
Índice de Atkinson-Plotnick & 0.0006 & 0.0014 & 0.0011 & 0.0006 & 0.0012 & 0.0004 \\
\hline
\end{tabular}

Fuente: Elaboración propia usando el módulo PROGRES desarrollado para Stata por Van Kerm y Peichl, (2007)

Musgrave y Thin (1948) proponen un índice denominado Efecto de Progresión (progresión efectiva), que es el resultado del cociente entre el coeficiente de igualdad después de impuestos y el coeficiente de igualdad antes de impuestos. El resultado del Índice se verá influenciado por la distribución de ingreso en la que se aplique: en el caso en que la distribución del ingreso antes de impuesto sea perfectamente igual, tanto la estructura de tasas proporcional o altamente progresiva tendrá un índice con un valor igual a 1; cuando la distribución del ingreso antes de impuesto sea desigual, la estructura de tasas progresiva dará como resultado un índice cuyo valor será mayor a 1 y; cuanto menos igual sea la distribución del ingreso antes de impuesto, la estructura de tasas progresivas tendrá más capacidad para igualar el ingreso. No obstante,

\footnotetext{
${ }^{7}$ Países que tienen fuertes efectos redistributivos como son los escandinavos en 2017 recaudaban por impuesto sobre personas más del $15 \%$ de su PIB, mientras que México en ese año tenía una recaudación no mayor al $3.5 \%$.
} 
si la estructura de tasas mantiene constante progresión o incluso se incrementa, en los niveles de ingreso más bajo el efecto será menor, de acuerdo con los datos de la Tabla 7, se tiene un efecto distributivo ligero que se mejora en 2015 y que puede ser el resultado del mejoramiento en la distribución y la progresividad lograda por la estructura de tasas (véase tabla 4).

Suits (1977) propone un índice en el cual, partiendo de la idea de la curva de Lorenz se establece una situación donde la carga impositiva es proporcional al nivel de ingreso, siendo el parámetro K el área debajo de la curva y el parámetro L el área que representa la estructura de tasas de impuestos sobre la relación de carga impositiva en correspondencia con el ingreso. Cuando la estructura de tasas del impuesto es proporcional el valor del índice será 0 , mayor que cero progresiva y regresiva menor que cero. Al igual que en la propuesta de Musgrave y Thin (1948) es importante tener en cuenta la distribución del ingreso sin impuesto, ya que como lo menciona Suits, ningún impuesto es regresivo por su naturaleza, tal es el caso del IVA que su regresividad se genera a partir de la distribución del ingreso, entre más desigual sea la distribución mayor será la regresividad. El índice de progresividad de Suits para los datos estudiados indica la existencia de progresividad.

Uno de los índices más usuales es el conocido índice de Progresividad de Kakwani (1977) que consiste en considerar el índice de concentración del impuesto y el coeficiente de Gini antes de impuestos, un valor positivo del índice indica un sistema tributario progresivo y un valor negativo indicará un sistema regresivo. Como se puede apreciar en la Tabla 7, el Índice de Kakwani es positivo en todos los años y se ha incrementado con el tiempo, aun cuando su progresividad es ligera ${ }^{8}$.

El Índice de Reynols y Smolensky (1977) es usualmente considerado como un índice de equidad vertical y puede ser derivado del índice de Kakwani y el nivel del impuesto ${ }^{9}$, de la Tabla 7 se desprende que la equidad vertical aun cuando baja se ha mantenido en el tiempo con un ligero avance marginal.

Por último, el índice de Atkinson (1970) y Plotnick (1981) es usado como una medida de desigualdad horizontal. De acuerdo con Plotnick (1981) la equidad horizontal consiste en que todos los iguales deben recibir el mismo trato, a un mismo nivel de bienestar obedece una misma obligación tributaria. En los casos en los cuales un proceso de redistribución altera el orden anterior estaría violentando la equidad horizontal. El índice indica la afectación que

\footnotetext{
${ }^{8}$ ¿Qué tan baja es la progresividad del índice de Kakwani (K) obtenida para el caso de México? En el año 2010 el coeficiente de Gini antes de impuesto y después de impuesto para México fue de 0.64 y $0.62 \%$ respectivamente. K fue de 0.08 y RS de 0.02 , los datos para un estudio similar presentado para Ecuador (Cano, 2017) reportaba para el año 2010 respectivamente los siguientes datos $0.64,0.63,0.30$ y 0.0071. El valor de K para Ecuador es cerca de 3.75 veces el de México, no obstante, tiene un efecto distributivo sumamente bajo. Lo cual deja claro que la progresividad del impuesto es importante pero el nivel es sustancial ${ }^{9} \mathrm{RS}=(\mathrm{t} /(1-\mathrm{t}) \mathrm{K}$, donde $\mathrm{t}$ es la tasa media efectiva y $\mathrm{K}$ el índice de Kakwani.
} 
tuvo la equidad vertical ante las actividades redistributivas, cuando el valor del índice es igual a cero quiere decir que no se tuvo afectación en la inequidad, porque la i-esima unidad más pobre en la base de la distribución previa es también la i-esima unidad más pobre después de la redistribución. El índice de Atkinson-Plotnick, que se presenta en la Tabla 7, resulta muy pequeño y a la baja, lo cual se puede interpretar como una situación en la cual el efecto de distribución no ha afectado de forma sensible a la equidad horizontal.

Los resultados obtenidos en la presente investigación son similares a los presentados por Vargas (2010), quien reporta ligera progresividad en el sistema fiscal que tiende a la proporcionalidad para el periodo de 1984-2002, en la cual los ingresos directos son progresivos, mientras que los indirectos resultan regresivos. También existen coincidencias con los resultados de Huesca y Araar (2016) que presentan evidencia de un incremento de la progresividad con niveles de polarización para el periodo 2002 a 2012, en la Tabla 7 se puede apreciar una mejoría en los índices para el año 2012, pero con una mayor progresividad en los deciles de menores ingresos que en los superiores como se aprecia en la Tabla 6.

\section{Conclusiones}

A lo largo del tiempo han sido diversos los estudios que han medido la progresividad de los impuestos a nivel nacional y a nivel América Latina, llegando a la conclusión de que cuando se estudian los impuestos personales existe cierto nivel de progresividad que es bajo y que en ocasiones no resulta suficiente para mantener una estructura de tasas en su conjunto progresivas. Normalmente los estudios toman vigencia ante alguna reforma que se dé en la estructura tributaria para tratar de conocer cuál es el resultado de la reforma en materia de equidad.

El presente documento al contar con información novedosa ofrece una oportunidad para abordar el tema. Regularmente las investigaciones que tratan de medir la redistribución del ingreso y la progresividad de la estructura de tasas de los impuestos para México lo hacen a través de la Encuesta Nacional de Ingresos y Gastos de los Hogares (ENIGH), lo novedoso de este documento consiste en la utilización de la información derivada de las declaraciones realizadas por los contribuyentes.

Para finalizar se puede destacar que el ISRPF ha sido progresivo y presenta efectos redistributivos, la progresividad del impuesto se ha mejorado a lo largo del periodo de estudio, los cambios realizados en 2013 y las adecuaciones a las tarifas han jugado de manera favorable para mejorar la distribución de la progresividad entre deciles, además de haber incrementado en un porcentaje importante el número de personas que realizaron sus declaraciones. Sin 


\section{E. Ramírez Cedillo / Contaduría y Administración 66(2), 2021, 1-27}

http://dx.doi.org/10.22201/fca.24488410e.2021.2654

embargo, el efecto de distribución es bajo y al ser tan solo una parte de la estructura tributaria es posible que se diluya con el efecto regresivo de los impuestos sobre el consumo.

\section{Referencias}

Amarante, V. y Colacce, M. (2018). ¿Más o menos desiguales? Una revisión sobre la desigualdad de los ingresos a nivel global, regional y nacional. Revista de la CEPAL, 124, 7-34. and Statistics, 63(2), 283-288. https://doi. org/10.18356/1d244513-es

Arnold, J. M. (2008). Do Tax Structures Affect Aggregate Economic Growth? Empirical Evidence from a Panel of OECD Countries. OECD Economics Department Working Papers. https://doi.org/10.1787/236001777843

Atkinson, A. (1970). On the Measurement of Inequality. Journal of Economic Theory, 2, 244-263. https://doi. org/10.1016/0022-0531(70)90039-6

Atkinson, A. (2015). Desigualdad ¿qué podemos hacer? Ed. Fondo de Cultura Económica, México.

Barreix, A. y Roca, J. (2007). Reforzando un pilar fiscal: el impuesto a la renta dual a la uruguaya, Revista CEPAL, 92, 123-142. https://doi.org/10.18356/5117f544-es

Biswas, S. Chakraborty, I y Hai, R. (2017). Income Inequality, Tax Policy, and Economic Growth. The Economic Journal, 127(601), 688-727. https://doi.org/10.1111/ecoj.12485

Bradley, S. (2018). Tax and inequality in the United States. Sociology Compass, 12, e12559. https://doi.org/10.1111/ soc4.12559

Cano, L. (2017). Personal income tax and income inequality in Ecuador between 2007 and 2011, CEPAL Review, 123, 56-75. https://doi.org/10.18356/f31c2017-en

Castañeda V. (2017). La equidad del sistema tributario y su relación con la moral tributaria. Un estudio para América Latina, Investigación Económica, 76 (299),125-152. https://doi.org/10.1016/j.inveco.2017.02.002

Castillo, M. (2015). La magnitud de la desigualdad en el ingreso y la riqueza en México, una propuesta de cálculo. CEPAL. Serie Estudios y Perspectivas 167.

Cepal (2018). El futuro de la igualdad en América Latina y el Caribe, ensayos breves. Cepal. Santiago.

Deaton, A. (2015). El gran escape, salud, riqueza y los orígenes de la desigualdad, Ed. Fondo de Cultura Económica, México.

Doerrenberg, P., y Peichl, A. (2013). Progressive taxation and tax morale. Public Choice, 155 (3/4), 293-316. https://doi.org/10.1007/s11127-011-9848-1

Dromel, N. y Pintus, P. (2004). Progressive Income Taxes as Built-In Stabilizers. Disponible en: https://pdfs. semanticscholar.org/fe70/b7d6ccbb166c8c566bb17d975af0b6b6430c.pdf y Consultado: 12/02/19

Dromel, N. y Pintus, P. (2008). Are Progressive Income Taxes Stabilizing? Journal of Public Economic Theory, 10 (3), 329-349.

Du, L. y Zhong, Z. (2018). Measuring the Redistributive Effects of China's Personal Income Tax. Asia and the Pacific Policy Studies, 5 (2), 220-234. https://doi.org/10.1002/app5.229

Engen, E. y Skinner J. (1999). Taxation and economic growth, en Tax Policy in the Real World, (ed.) J. Slemrod, Cambridge University Press, New York, 305-330. https://doi.org/10.1017/cbo9780511625909.021

Esquivel, G. (2015). Desigualdad extrema en México, Concentración del poder económico y político. Oxfam México. Disponible en: https://www.oxfammexico.org/sites/default/files/desigualdadextrema_informe.pdf y Consultado: $28 / 03 / 19$

Estrada, F., y González I. (2014). Tax policy and fiscal economy approaches Hayek and Brennan/Buchanan. Disponible en: https://www.researchgate.net/publication/276918950 y Consultado: 24/04/19

FMI (Fondo Monetario Internacional) (2017). México: 2017 Article IV Consultation-Press Release; and Staff Report, IMF Country Report No. 17/346 
Friedman, M. (1948). A Monetary and Fiscal Framework for Economic Stability, The American Economic Review, 38(3), 245-264. https://doi.org/10.1007/978-1-349-24002-9_19

Fuentes-Nieva. R., y Galasso. N. (2014). Working for the Few: Political capture and economic inequality. Oxfam. Disponible en: https://oxfamilibrary.openrepository.com/bitstream/10546/311312/3/bp-working-for-few-political-capture-economic-inequality-200114-es.pdf y Consultado: 22/04/19

Goldschmidt, A. (1941a). El Impuesto Progresivo: historia, teoría y práctica. Investigación Económica 1(1), 85-114.

Goldschmidt, A. (1941b). El Impuesto Progresivo: historia, teoría y práctica. Investigación Económica 1(2), 209-244.

Hardoon. D. (2017). An Economy for the 99\%: It's time to build a human economy that benefits everyone, not just the privileged few. Oxfam. https://doi.org/10.21201/2017.8616

Hardoon. D., Fuentes-Nieva. R., y Ayele. S. (2016). An Economy For the 1\%: How privilege and power in the economy drive extreme inequality and how this can be stopped. Oxfam. https://doi.org/10.21201/2016.592643

Huesca, L. y Araar, A. (2016). Comparison of fiscal system progressivity over time: theory and application in Mexico. Estudios Económicos, 31 (1), 3-45.

Kakwani, N. (1977). Measurement of Tax Progressivity: An International Comparison. The Economic Journal, 87, 71-80. https://doi.org/10.2307/2231833

Koester, R y Kormendi R. (1989). Taxation, aggregate activity and economic growth: crosscountry evidence on some supplyside hypotheses, Economic Inquiry, 27, 367-386. https://doi.org/10.1111/j.1465-7295.1989. tb02011.x

Krajewski, P. y Pilat, K. (2017). Does A Progressive PIT Stabilize the Economy? A Comparison of Progressive and Flat Taxes. Comparative Economic Research, 20 (1), 21-34. https://doi.org/10.1515/cer-2017-0002

Lange, M., Wondo. Q., y Carey. K. (2018). The Changing Wealth of Nations 2018. Banco Mundial. Disponible en: https://openknowledge.worldbank.org/handle/10986/29001 y Consultado: 11/05/19

Mahon, J., Bergman M., y Arnson C. (2015). Igualdad a través de una reforma fiscal progresiva. Política Exterior, 29 (166), 94-108.

Malo, V. y Vélez R. (coords.), (2012). El México del 2012. Reformas a la Hacienda Pública y al sistema de protección social. México, Centro de Estudios Espinoza Yglesias.

Massina, J., y Silva J. (2017). Desigualdad del ingreso en América Latina, comprendiendo el pasado para comprender el futuro. Banco Mundial. Disponible en: Desigualdad del ingreso en América Latina (worldbank.org) y Consultado: 17/04/19

Mullainathan, S., y Shafir, E. (2016). Escasez ¿por qué tener poco significa tanto? Ed. Fondo de Cultura Económica, México.

Musgrave, R. (1966). Principles of budget determination en: Public Finance: Selected Readings eds. H. Cameron and W. Henderson. New York: Random House.

Musgrave, R. y Thin, T. (1948). Income tax progression 1929-48. The Journal of Political Economy, 56: 498-514. https://doi.org/10.1086/256742

OXFAM, (2015). Riqueza: Tenerlo Todo y Querer Más. Disponible en: Riqueza: tenerlo todo y querer más (oxfam. org) y Consultado: 17/02/19

Padovano, F. y Galli E. (2007). Tax rates and economic growth in the OECD countries (19501990), Economic Inquiry 39(1), 44-57. https://doi.org/10.1111/j.1465-7295.2001.tb00049.x

Pedersen, J. (2018). Just inheritance taxation. Philosophy Compass 13, e12491. https://doi.org/10.1111/phc3.12491

Piketty, T., y Qian, N. (2009). Income Inequality and Progressive Income Taxation in China and India, 1986-2015. American Economic Journal: Applied Economics, 1 (2), 53-63. https://doi.org/10.1257/app.1.2.53

Piketty, T., y Saez, E. (2013). A theory of optimal inheritance taxation. Econometrica, 81 (5), 1851-1886. https:// doi.org/10.3982/ECTA10712

Piketty. T. (2014). El capital en el siglo XXI. Ed. Fondo de Cultura Económica, México, 695.

Pinto, J. (2012). Los orígenes del impuesto directo y progresivo en América Latina. Historia y Sociedad, 23, 53-77.

Plotnick, R. (1981). A Measure of Horizontal Equity. The Review of Economics, 63(2), 283-288. https://doi. org/10.2307/1924099 
Ramírez. E. (2007) Crítica a la estructura tributaria actual en México. Contaduría y Administración, FCA-UNAM, 223, 113-134. http://dx.doi.org/10.22201/fca.24488410e.2007.620

Ramírez, E. (2012). La reforma fiscal en México. Teoría y Práctica fiscal en un contexto globalizado. Colombian Accounting, Universidad de Medellín, 4, 81-108.

Ramírez. E. (2019). México, entre la recaudación y la distribución: lecciones desde Escandinavia. En Políticas Públicas y cambio de régimen en México, UAMI, 153-181.

Ramírez E. (2013). La generalización del Impuesto al Valor Agregado ¿una opción para México?, Revista Mexicana de Ciencias Políticas y Sociales, Nueva Época, LVIII (219), 75-102.

Reynolds, M. y Smolensky, E. (1977) Public Expenditure, Taxes and the Distribution of Income: The United States. 1950, 1961, 1970. New York, NY: Academic Press.

Rick, S., Paolacci, G., y Burson, K. (2018) Income tax and the motivation to work. J Behav Dec Making, 31, 619-631. https://doi.org/10.2139/ssrn.2655424

SAT (2015b) Reporte anual 2015 y Retos 2016, Disponible en: http://omawww.sat.gob.mx/cifras_sat/Documents/ ReporteAnual2015_Retos2016.pdf y Consultado: 18/01/19

SAT (2015a) Informe tributario y de gestión para el cuarto trimestre de 2015, Disponible en: http://www.sat.gob. $\mathrm{mx} /$ transparencia/transparencia_focalizada/Documents/itg2015_t4/ITG_T4_2015.pdf y Consultado: 18/01/19

SAT (2018) Información para dar cumplimiento al artículo décimo noveno transitorio de la LIF 2017. Disponible en: http://omawww.sat.gob.mx/cifras_sat/Documents/Lineamientos_art\%C3\%ADculo19LIF.pdf y Consultado: 22/03/19

Scheve, K. y Stasavage, D. (2016) Taxing the Rich A History of Fiscal Fairness in the United States and Europe. Princeton University Press, Princeton, New Jersey, 288.

Slemrod, J. (1998) The Economic of taxing the rich. NBER, WP 6584. Disponible en: The Economics of Taxing the Rich | NBER y Consultado: 21/01/19

Splinter, D. (2018) Who pays no tax? the declining fraction paying income taxes and increasing tax progressivity. Contemporary Economic Policy. https://doi.org/10.1111/coep.12407

Stiglitz, J. (2012) El precio de la desigualdad. Ed. Taurus. Madrid

Suits, D. (1977) Measurement of Tax Progressivity. American Economic Review, 67, 747-752.

Tanzi, Vito, (2003). La globalización y la necesidad de una reforma fiscal en los países en desarrollo. En Integración y Comercio. pp. 3-20.

Van Kerm, P. y A. Peichl (2007). Progress: Stata module to measure distributive effects of an income tax. Statistical Software Components, No. S456867, Boston College

Vargas, C. (2010) ¿Es redistributivo el sistema fiscal en México? La experiencia de 1984-2002. Estudios Sociales, 18 (35), 53-97.

Widmalm, F. (2001) Tax Structure and Growth: Are Some Taxes Better Than Others? Public Choice, 107 (3/4), 199-219. 